\section{Brain Drain of African Scholars and the Role of Studying in the United States}

\section{Damtew Teferra}

Damtew Teferro is a doctoral student in the School of Education, Center for International Higher Education, Boston College. Address: Campion Hall, 140, CommonwealthAvenue, Chestnut Hill, MA 02 167, USA; fox; (6) 기 552 8422; email: feferra@tony.bc.edu.

$\mathrm{T}$ he term "brain drain" is often used to describe the flow of scholarsfrom one country-especially a Third World one-to another-usually a developed one. There has been some controversy over the concept. Some refute concerns over brain drain as emotional nationalistic nonsense while others urge a serious commitment by developing countries particularly in Africa to staunch their serious brain drain. While one school of thought treats brain drain as a n extreme form ofinstitutional nomadism another views it as a circulation of skilled labor in the emerging interdependent global economy.

\section{THE INTERNATIONAL DIMENSION OF BRAIN DRAIN}

Since the mid-1960s and, in particular, during the 1970s, the geographic structure of the brain drain process noticeably changed, the developing countries becoming its "nutrient medium." During the period from 1961 to 1980, more than 500,000 scholars from the developing countries moved to the United States. Great Britain. and Canada.

In Eastern Europe brain drain is a very recent phenomenon. For many decades brain drain was largely unknown to the former Soviet Union and existed as a thin stream in a relatively weak current of ethnic emigration involvingmainly Jews and Germans. Emigration itself was either ignored or regarded by the society as a phenomenon incompatible with the socialistsystem or even as high treason. The state of brain drain has now reached a crisis level due to the liberalization of immigration laws in these countries. It costs U.S.\$2.5-5 billion in annual potential loss to Russia alone. Between 1981 and 1991, 50,000 high-skill specialists left Bulgaria,while Hungary has lost 15 percent of its scientistsand specialists and Poland 10 percent of its total scientific personnel.

In Asia, the loss of 15,000 medical doctors in 1980 cost India U.S.\$144 million. The Chinese Communist revolution of 1949 and the recent incident in Tiananmen Square, which resulted in immigration measures by the U.S. government stimulated brain drain from China. The Asian student population in the United States grew by more than 8 percent over a period of 15 years from 1974/75 to 19911 92, which is indicative of the growth of the pool of potential stay-ons.

\section{During the periad from 1961 to 1980 , more than 500,000 scholars from the developing counfries moved io the United States, Greaf Britain, and Canada.}

Although the data for Africa is very scanty, sourcesindicate that the figure for immigrant scholars and stay-ons is very high as compared to the small critical mass of its trained and qualified scholars. Britain, for example, plays .host to over 8,000 recent Somali refugees, many of whom are businessmen and academics. A 1985 World Bank report reveals that more than 70,000 trained Africans have chosen to remain in Europe; in the United States about half that figure, may also stay on there.

\section{AFRICAN SCHOLARS IN THE UNITED STATES}

With its diverse and huge higher education system, scholarship opportunities, and less-stringent immigration policies, the United States has been a more attractive market for pursuing scholarship than the rest of the Westem world. It should be pointed out that the United States still has a more favorable immigration policy for trained professionals.

Opportunities for higher education, especially graduate studies, are extremely limited and fiercely competitive at home. Thus, there is a steady flow of African immigrants to the United States in pursuit of academic excellence. In 1986/87 over 31 ,000African students traveled to the United States: 48.2 percent from the west, 20.9 percent from the east, 17.3 percent from the north, and 16 percent from the south. For the last four decades Nigeria, Egypt, South Africa, Ethiopia, Kenya, and Liberia stood as the leading sendernations. Roughly41 percent of African studentswere studying at the graduate level during the 1987/88 academic year while 55 percent were at the undergraduate level.

Many sources and personal observation support the view that most African scholars and students prefer to stay in the United States rather than other Western countries. In Addis Ababa University, Ethiopia - where the author has worked for over 10 years - of about 20 faculty from the Physics Deparhnent who left for Ph.D. studies - almost all to the United States - nonereturned. It is, however, inter- 
esting to note that almost all who studied in Europe, the old East Bloc, and Scandinavia returned. The Mathematics Deparhnent also suffers from the same problem and has to recruit fresh graduates almost every year. These trends correspond quite well with the general view that immigrant scholars of science background have better job opportunities in the American market than do their counterparts in the humanities and social sciences.

It must be remarked that job opportunities, whether professional or otherwise, are far better for African scholars in the United States than in Europe, where the unemployment rate is high. This is one of the major factors that keeps professionals in the United States. A lenient immigration policy, better job prospects, and less segregating sociocultural setting attract African scholars to stay in the United States.

With its diverse and huge higher edu-
cation system, scholarship opportuni-
ties, and less-stringent immigration
policies, the United States has been a
more attractive market for pursuing
scholarship than the rest of the West-
ern world.

\section{BRAIN DRAIN WITHIN AFRICA}

The flow of scholars from one developing country to another is not usually conceived as brain drain -in the accepted sense. It is treated as a sign of solidarity, cooperation, and collaboration among those underdeveloped countries as a collective effort toward socioeconomic development.

Many African scholars work across their boarders to meet the need for professionals in many African institutions. The preference of recruiting professionals from abroad in most African institutions is changing in favor of African scholars for social, economic, cultural, and scientific reasons.

Sociocultural Setting: African scholars are better able to adapt and work within the continent where the sociocultural realities are very similarin many countries of the region. This may also be the case with muslims who travel across the continent into the Middle East.

Scientific Approaches: African-trained scholarshave lived with the underlying problems of the continent. This gives them a competitive advantage over other scholars in approaching, assessing, and solving problems. Many problems in Africa are common and interrelated; well-informed, experienced, and indigenous scholarship is required for sustainable socioeconomic development. It has now become clear that many overseas consultants, especially from the West, who are usually on short-term contracts, are short-sighted with regard to the complex social, cultural, political, and economic as well as regional and local realities of the continent.

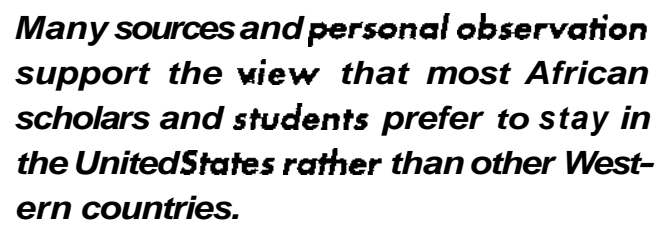

Economic Benefits: Many African scholars value the opportunity of working abroad in areas of their expertise, which usually comes with good financial remuneration. Still the cost of employing these scholars is often lower for the recruiting body than emplying their Western counterparts. Western scholars have become so expensive that, even purchasing a round-trip ticket for external examiners has become almost impossible for most African institutions.

The movement of African scholars within the region, however, is not always full of happy stories. The massive outflow in some countries of southern Africa has reached such staggering proportions that it bas caused severe shortages of personnel. Zambia, Malawi, and Zimbabwe had a flood of scholars to Botswana, South Africa, Swaziland, and Namibia, creating severe shortages at home.

\section{Efforts to Halt Brain Drain}

Variousnational, regional, and intemational effortsare now underway to curtail the problem. Recently, in one prominent intemational initiative, the United Nations Development Program and the International Organization for Migration have undertaken to attract African scholars who are resident in the United States to work in Africa. Through the TOKTEN (Transfer of Knowledge through Expatriate Nationals) program, UNDP recruited many professionals including Africans in developed countries to volunteer their services for short, well-prepared consultancy assignments in their countries of origin. A number of African governmentshave also taken measures to attract their schol- 
ars living abroad by providing free housing, duty-free status, and other benefits.

Some ill-advised national initiatives to avert the wave of immigration have, however, resulted in adverse consequences. Strict regulations hindering the exodus of scholars and students, as a measure to curb brain drain, ended up discouraging prospective returnees.

The motivation of African scholars to study in the United States and stay on later is a result of complex economic, political, social, cultural, and personal matters.

\section{SUMMARY AND RECOMMENDATIONS}

The motivation of African scholars to study in the United States and stay on later is a result of complex economic, political, social, cultural, and personal matters. The impact of each fąctor varies from country to country and from individual to individual.

Many African countries are now undergoing economic hardships exacerbated by political turmoil and social instabilities making it difficult for scholars to return home. Furthermore, the news from home on suppression of dissidents by governments aggravated by the ever-declining support for public services discourages potential returnees.

African governments should wholeheartedly embrace the fact that scholars are the center of development, selfreliance, and sustainability. This should be accompanied by the commitment of more resources and autonomy, responsibility, academic freedom, and good working facilities, not only to encourage those scholars abroad to return but also to discourage those at home from fleeing, ultimately strengthening the nation-building capacity.

\section{REFERENCES}

Hyaeweol Choi, An Intemational Scientific Community: Asian Scholars in the United States (Westport, Conn.: Praeger, 1995).

Stanislav Simanovsky, Margarita P. Streptova, and Yuny G. Naido, Brain Drain from Russia: Problems. Prospects and Ways of Regulation (New York: Nova SciencePublishers, 1996).

Emeka Jonathan Okoli, Organizational Entry, Socializations, and Assimilation: A Study of "Brain Drain" and the Assimilation of African Students into the American Culture. Ph D Dissertation, Howard University, 1994.

Caiphas T. Nziramasanga, Political Implications ofthe Southern Development in the Region (paper presented at Indiana University's African Studies Center, March 31 -April 1, 1995).

\section{An Asian Focus \\ We feature in this issue several articles considering aspects of Asian higher education. One of the most dynamic regions of the world, the Asian Pacific Rim is the scene of several of the world's most rap- idly changing academic systems. The articles in this section highlight several key elements of current Asian higher education development.}

\section{Cosmopolitanism Run Amok: Work and Rewards in Asia's Universities}

\section{Philip G. Altbach}

Philip G. Altboch is Monan Professor of Higher Education at Boston College.This article appeared in the South China Morning Post (Hong Kongl.

he policymakers who run Hong Kong's higher edu-
cation system, in an effort to ensure that academic staff are both productive and measure up to their colleagues in other counmes, have placed Hong Kong's scholars and scientists in an unfortunate straitjacket. They are strongly encouraged to publish their work mainly in recognized international journals and with "gold standard" international publishers. Work published locally does not count for much in the increasingly competitive world of academe, where assessment and accountability are the slogans of the day and everything must be measured to ensure productivity.

\section{International validation of academe has deep mots in Hong Kong, as well os in other Asian university sysfems.}

The idea is that Hong Kong scholars and scientists should be competing with their colleaguesoverseas in such intellectual centers as the United States and Britain.Just as Hong Kong competes with the rest of the world economically, it should likewise be able to compete intellectually. There is also an underlying assumption that local journals and publishers cannot meet international standards. For example, it is charged that publications are not "refereed' anonymously evaluated by peers in the field-or that even if they are subject to peer review, standards are somehow inadequate. The local academic community is not trusted to adequately judge quality, and foreign experts must play 